\title{
ROTEIROS DE PRÁTICAS AMBIENTAIS PARA MONITORIA DE VISITAS ESCOLARES AO JARDIM BOTÂNICO DA UFSM NA PERSPECTIVA DA ECOALFABETIZAÇÃO
}

\author{
Simone da Rosa Messina ${ }^{1}$, Ana Maria Thielen Merck² \\ ${ }^{1}$ Licenciada em Ciências Biológicas e Especialista em Educação Ambiental UFSM. \\ ${ }^{1}$ Profa Dra Adjunta do Depto de Biologia UFSM \\ simessina@gmail.com, anamariathielenmerck@gmail.com
}

\section{RESUMO}

A Alfabetização ecológica é a leitura e interpretação da natureza que permite ver o homem como parte integrante da teia da vida. Tal abordagem configura-se numa grande contribuição para a prática da educação ambiental tanto no ensino formal quanto informal. Neste sentido, as práticas ambientais encontram nos jardins botânicos espaços naturais de grande biodiversidade e valor educativo. $O$ objetivo deste trabalho foi oferecer aos monitores de educação ambiental do Jardim Botânico da UFSM, roteiros de práticas ambientais para monitoria de visitas escolares, direcionadas aos estudantes da educação infantil e ensino fundamental. A metodologia do trabalho consistiu no levantamento de atividades práticas em bibliografias eletrônicas e impressas, assim como elaboração de atividades selecionadas conforme os Parâmetros Curriculares Nacionais (PCNs). Estas práticas foram adaptadas ao contexto do Jardim Botânico da UFSM e organizadas sob a perspectiva da Ecoalfabetização. Os roteiros compreendem vinte e oito práticas ambientais, sendo seis indicadas para a educação infantil e vinte e duas para o ensino fundamental. Destas, foi selecionada uma prática para exemplificação, implementada com os alunos da terceira série do ensino fundamental do Colégio Riachuello. Os resultados demonstraram que as práticas ambientais além de serem facilitadoras do trabalho de educação ambiental dos monitores do Jardim Botânico da UFSM, também são estratégias de ensino para os professores e de aprendizagem para os estudantes. Esta monografia de Especialização em Educação Ambiental (PPGEA-UFSM), foi defendida em dezembro de 2010.

Palavras-chaves: educação ambiental, ecoalfabetização, jardim botânico, práticas ambientais

\section{ABSTRACT}

Ecological Literacy is the reading and interpretation of nature that allows to see the man as an integral part of the life's web. This approach sets up a great contribution to the practice of environmental education in both formal and informal education. In this sense, the environmental practices find in the botanical gardens, natural areas of big biodiversity and educational value. The objective of this work was offer to environmental education monitors of the Botanic Garden 


\section{(Revista Eletrônica do PPGEAmb-CCR/UFSM) ISSN:}

UFSM, scripts for monitoring of environmental practices of school visits, directed to students from kindergarten and elementary school. The research methodology was done in practical activities in electronic and printed bibliographies, as well as preparation of the selected activities according to the National Curricular Parameters (PCNs). These practices have been adapted to the context of the Botanical Garden UFSM and organized from the perspective of Ecoliteracy. The itineraries include twenty-eight environmental practices, six of them, indicated for kindergarten and twentytwo for elementary school. One of them, was selected for exemplification, implemented with the third graders of elementary school of the Riachuello School. The results showed that the environmental practices beyond being facilitators of environmental education work of the monitors of the Botanical Garden UFSM are also teaching strategies for teachers and learning for students. This monograph of Specialization in Environmental Education (PPGEA-UFSM) was submitted in December 2010.

Keywords: environmental education, eco-literacy, botanical garden, environmental practices

\section{INTRODUÇÃO}

O mundo tem passado por transformações em todos os aspectos e os velhos paradigmas cartesianos em relação à percepção do ambiente não se adaptam mais ao mundo contemporâneo do qual emerge a necessidade de novos paradigmas para a resolução dos problemas ambientais.

O ambiente quando visto sob ótica cartesiana fica reduzido a uma análise individual de suas partes, sem levar em consideração a sua estrutura global ou sistêmica. Esta crise de percepção se configura como uma das principais razões dos problemas ambientais atuais.

Para superar a lógica econômica insustentável decorrente da visão cartesiana torna-se necessária uma nova percepção que oriente uma racionalidade ambiental (LEFF 2006). A busca de uma nova visão do ambiente fundamentada no holismo e voltada para a complexidade das relações entre o ambiente e os seres vivos é, possivelmente, uma solução para os problemas ambientais deste século.

A nova percepção ambiental surge a partir de uma nova forma de ler, interpretar o ambiente e seus recursos naturais. Esta nova percepção ambiental, de leitura e interpretação do ambiente pode ser considerada uma nova alfabetização: a Alfabetização Ecológica (CAPRA 2002).

Capra (2002) define que ser ecologicamente alfabetizado significa compreender os princípios básicos de organização das comunidades ecológicas e ser capaz de incluí-los na vida diária das comunidades humanas, e que este ensino será o papel mais importante da educação no próximo século.

As áreas naturais oferecem diversas possibilidades para o desenvolvimento de metodologias práticas de educação ambiental. Neste sentido, os jardins botânicos são áreas protegidas no seu todo ou em parte, por coleções de plantas vivas cientificamente, organizadas, documentadas e identificadas com a finalidade de estudo, pesquisa e documentação do patrimônio florístico do país, acessível ao público, no todo ou em parte, servindo à educação, à cultura, ao lazer e à conservação do meio ambiente. (CONAMA 2003) 


\section{(Revista Eletrônica do PPGEAmb-CCR/UFSM) ISSN:}

No Jardim Botânico da UFSM, a Alfabetização Ecológica surgiu como tema de projeto de extensão, desde 2007, para servir a demanda de visitas das escolas de ensino básico de Santa Maria e região. A principal justificativa deste trabalho foi a necessidade de ampliar a proposta de educação ambiental no Jardim Botânico da UFSM e apresentar aos monitores de educação ambiental, um guia de trabalho, apresentando atividades mais elaboradas e seguindo os Parâmetros Curriculares Nacionais (PCNs) em função da demanda das escolas. O objetivo do trabalho foi desenvolver roteiros de práticas ambientais para a monitoria de visitas escolares da educação infantil e do ensino fundamental ao Jardim Botânico da UFSM sob a perspectiva da Ecoalfabetização.

Considerando que a sensibilização e o desenvolvimento de competências são alguns dos objetivos da Educação Ambiental, as práticas ambientais e as trilhas ecológicas configuram-se como estratégias pedagógicas produtivas para o desenvolvimento de projetos educativos. Dentre as práticas ambientais estão os jogos cooperativos, as dinâmicas de grupo realizadas a partir de temas ambientais e as trilhas ecológicas como percursos construídos que permitem a interpretação da natureza.

É necessária uma educação ambiental que aproxime os estudantes com a natureza, gerando vínculos emocionais a fim de permitir ampliação de percepções e até de atitudes. A ecoalfabetização aliada ao pensamento complexo são as chaves para uma educação ambiental efetiva no século XXI.

\section{METODOLOGIA}

O trabalho foi desenvolvido em três etapas básicas: levantamento bibliográfico, construção do roteiro de práticas ambientais e implementação de uma prática como exemplificação.

Na primeira etapa realizou-se um estudo bibliográfico sobre alfabetização ecológica e práticas ambientais. Na sequência, foi realizado um levantamento de práticas ambientais em bibliografias eletrônicas e impressas. As atividades foram selecionadas segundo os Parâmetros Curriculares Nacionais (PCNs) para a educação infantil e ensino fundamental, e adaptadas para implementação no Jardim Botânico da UFSM. Algumas práticas foram elaboradas especialmente para o contexto do Jardim Botânico.

Todas as atividades pesquisadas e adaptadas formaram roteiros de práticas ambientais que ficarão disponíveis aos monitores de educação ambiental no Jardim Botânico da UFSM, para implementação durante as visitas escolares. Os roteiros foram organizados em níveis de ensino: educação infantil e ensino fundamental (séries iniciais e séries finais). A escolha destes níveis de ensino está relacionada com o público visitante predominante do Jardim Botânico, registrado pelo livro de visitas. As práticas ambientais foram organizadas em: título, conteúdo, objetivos, princípios ecológicos, no de participantes, duração, material necessário e procedimentos. Os princípios ecológicos ${ }^{3}$ seguem CAPRA (2002). Além dos roteiros de práticas ambientais, foi desenvolvido um guia de instruções e procedimentos para os monitores de educação ambiental do Jardim Botânico da UFSM.

\footnotetext{
${ }^{3}$ Princípios ecológicos: Redes, Sistemas, Diversidade, Energia, Equilíbrio Dinâmico e Ciclos.
} 


\section{(Revista Eletrônica do PPGEAmb-CCR/UFSM) ISSN:}

No terceiro momento foi selecionada uma prática ambiental para implementação no Jardim Botânico no intuito de obter dados a respeito da viabilidade e produtividade das práticas. Para implementação dos roteiros de práticas no Jardim Botânico, foi escolhida a escola de ensino fundamental Colégio Riachuello, localizado no bairro Camobi, Santa Maria, RS.

No dia da visita ao Jardim botânico da UFSM, foi solicitado aos trinta e sete alunos participantes que desenhassem sua pré-percepção a respeito do Jardim Botânico, respondendo a pergunta: Para você o que é um jardim botânico?

Ao chegar, a turma foi recepcionada no espaço chamado "círculo da vida", onde recebeu as boas vindas da monitora e foi orientada sobre a prática ambiental: Ecodetetives: Trilha Teia da vida. A turma foi dividida em duas equipes proporcionais: a equipe azul e a equipe vermelha. Cada equipe teve como monitoras as professoras regentes das turmas, que estiveram à disposição para orientar e tirar dúvidas quando necessário. As professoras, em momento algum, poderiam dar as respostas, apenas dicas para os alunos refletirem. Durante a trilha havia dez desafios amarrados em dez árvores diferentes para cada equipe com fitas da sua respectiva cor. As equipes foram conduzidas até o início da trilha onde foram orientando-se pelas fitas de sua cor que estavam atadas com o desafio preso em determinadas árvores do Jardim Botânico. Um aluno da equipe por vez leu o desafio para os colegas que refletiram, responderam. Uma colega foi designada para fazer as anotações. As respostas anotadas juntamente com os desafios foram guardados nos envelopes azul para a equipe azul e vermelho para a equipe vermelha.

Ao final da trilha houve uma missão surpresa para as equipes: criar uma poesia ou uma música que expressasse o que foi visto durante a trilha. Após realizarem a atividade, as equipes retornaram ao círculo da vida, onde trocaram os envelopes. A equipe azul leu o desafio e a resposta da equipe vermelha e julgou se estava correto ou não. $E$ a equipe vermelha fez o mesmo.Cada resposta correta valeu 5 pontos para o MEIO AMBIENTE e cada resposta incompleta valeu 3 pontos. Antes de somar os pontos, cada equipe apresentou aos colegas a missão surpresa que valeu 10 pontos para o MEIO AMBIENTE.

De volta à escola, os alunos desenharam a sua percepção após a visita ao Jardim Botânico, e os professores também avaliaram as atividades.

Os alunos fizeram desenhos de pré-percepção, antes da visita, e de pós-percepção, depois da visita ao Jardim Botânico. Nesta fase foram avaliadas as percepções dos estudantes relativas ao Jardim Botânico.

Para a pesquisa, foi adotada a abordagem qualitativa, utilizando-se da lógica da compreensão dos fenômenos por sua descrição e interpretação, a partir da observação direta dos participantes na prática, e da análise dos desenhos de pré e pós- percepção.

\section{RESULTADOS E DISCUSSÃO}

Os roteiros compreendem vinte e oito práticas sendo vinte adaptadas e oito elaboradas para o contexto do Jardim Botânico da UFSM. São seis práticas ambientais indicadas para a educação infantil, nove para séries iniciais (1aㅡ $2^{a}$ e e $3 \underline{a}$ ), dez para séries finais (5a e 6aㅡ) e três, em especial, para 4ạ e 7ạ série (conteúdo comum: corpo humano). As atividades são flexíveis, 
permitindo ao monitor realizar as práticas conforme a abordagem dos conteúdos de cada série de ensino. Além disso, neste mesmo material, estão disponíveis aos monitores todas as instruções necessárias sobre como proceder com as escolas, desde a divulgação, recepção, desenvolvimento das práticas e conclusão da visita.

Para analisar o impacto da prática para as crianças foi realizada uma análise dos desenhos representativos de pré-percepção e pós-percepção, comparados (Quadro 1) e discutidos na seqüência.

Ao final da prática "Trilha Teia da vida", as duas equipes empataram na pontuação com 56 pontos cada. Somando a pontuação das equipes obteve-se 112 pontos. Os pontos foram somados porque a atividade foi cooperativa e não competitiva, por isso quem na verdade "ganhou" com os conhecimentos dos estudantes, mesmo que indiretamente, foi o meio ambiente. A pontuação total atingida pelas equipes que acertaram a maior parte dos desafios demonstrou que os estudantes possuem conhecimentos em relação à natureza e os seres vivos o que poderá aumentar as chances dos estudantes conservá-lo, já que só se cuida o que se conhece. Além disso, foram analisados os desenhos de pré e pós-percepção em relação ao Jardim Botânico. Abaixo apresenta-se o quadro comparativo de percepções e sua discussão:

\section{Quadro1: QUADRO COMPARATIVO DE PERCEPÇÕES}

\begin{tabular}{|c|c|c|}
\hline Elementos representados & $\begin{array}{c}\text { Pré- percepção } \\
(\%)\end{array}$ & $\begin{array}{c}\text { Pós- percepção } \\
(\%)\end{array}$ \\
\hline Plantas & $97,3 \%$ & $100 \%$ \\
\hline Animais & $31,5 \%$ & $28,5 \%$ \\
\hline Construções humanas & $52,6 \%$ & $45,7 \%$ \\
\hline Presença humana & $18,4 \%$ & $45,7 \%$ \\
\hline Fatores abióticos & $52,6 \%$ & $65 \%$ \\
\hline
\end{tabular}

Foram 37 desenhos de pré-percepção e 37 desenhos de pós-percepção analisados. Segundo o Quadro comparativo de percepções, os elementos representados nos desenhos de prépercepção, as plantas foram predominantes, representadas de uma forma bem genérica em: árvores, gramíneas e flores. Apenas uma criança não apresentou plantas em seu desenho constituído de um lago e uma ponte, demonstrando que esta provavelmente nunca foi a um jardim botânico ou não tinha a mínima idéia do que se tratava. Os animais mais representados nos desenhos foram pássaros, borboletas e peixes o que correspondeu com boa parte da fauna existente no Jardim Botânico. Também houve uma representação de uma cobra, um veado, um sapo e uma tartaruga. Nas construções humanas, predominaram as trilhas além de algumas pontes. Nos elementos naturais não vivos foram representados: sol, água, solo e nuvens. Quanto à presença humana apenas $18,4 \%$ foram considerados. Possivelmente este fator vem de uma visão na qual o homem é superior ou encontra-se fora da natureza. Também não podemos descartar a possibilidade dos resultados relativos à pré-percepção dos alunos sofrerem influência pelas professoras ao comunicarem a visita ao Jardim Botânico e as trilhas, isso explicaria a predominância das plantas e das trilhas e poucos animais nos desenhos.

Nos desenhos de pós-percepção, todas as crianças representaram as plantas, a maioria ainda como árvores genéricas, mas houve alguns desenhos que representaram parte da flora real do Jardim Botânico como os cactos e os bambus. Quanto à representação dos animais houve uma 


\section{(Revista Eletrônica do PPGEAmb-CCR/UFSM) ISSN:}

diminuição de $3 \%$ em relação ao desenho de pré-percepção e não há um motivo aparente para esta diminuição. O que poderíamos supor é que talvez os alunos não prestaram muita atenção nos animais, dando mais ênfase na plantas. Em relação as construções humanas também houve um decréscimo de $6,9 \%$, as trilhas e pontes foram mantidas e a novidade foi a representação dos bancos do círculo da vida.

O fato que mais chamou atenção foi a pós percepção relativa a presença humana que aumentou em $31 \%$. Observa-se aqui que aproximadamente metade das crianças (45\%) passaram a considerar os seres humanos no ambiente, o que contribui para uma visão de todo ou sistêmica na ecoalfabetização. Quanto aos fatores abióticos houve um aumento de 7\%, demonstrando que os estudantes observaram além da fauna e da flora do ambiente.

Todos estes resultados indicam que a maioria das crianças já possuía uma percepção do que há num jardim botânico e que esta percepção sofreu poucas alterações após a visita. Foi possível notar que possivelmente os alunos imaginavam que num jardim botânico só existissem árvores. Pelos resultados dos desenhos, é possível observar que a percepção pode até ser ampliada, porém sua mudança é um processo lento que não apresenta grandes resultados em uma única prática. Além disso, alguns fatores talvez influenciaram a representação das percepções em desenho, como o diálogo com os colegas, ou a visualização do desenhos de outro colega, a intervenção dos professores, a falha na própria forma de solicitação dos desenhos, assim como situações que chamam a atenção individualmente. Portanto a análise da evolução de percepção ambiental é um processo bastante complexo que necessita de tempo, de várias práticas e representações para se obter resultados mais concretos. Observe abaixo alguns desenhos de pré e pós-percepção:

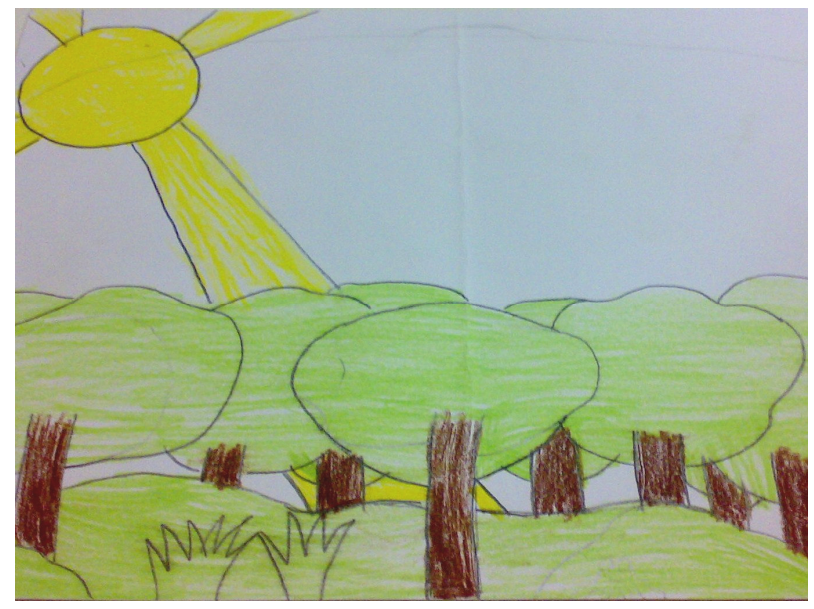

Figura 1 Desenho de pré-percepção 1 
(U)

\section{Monografias Ambientais}

\section{(Revista Eletrônica do PPGEAmb-CCR/UFSM) ISSN:}

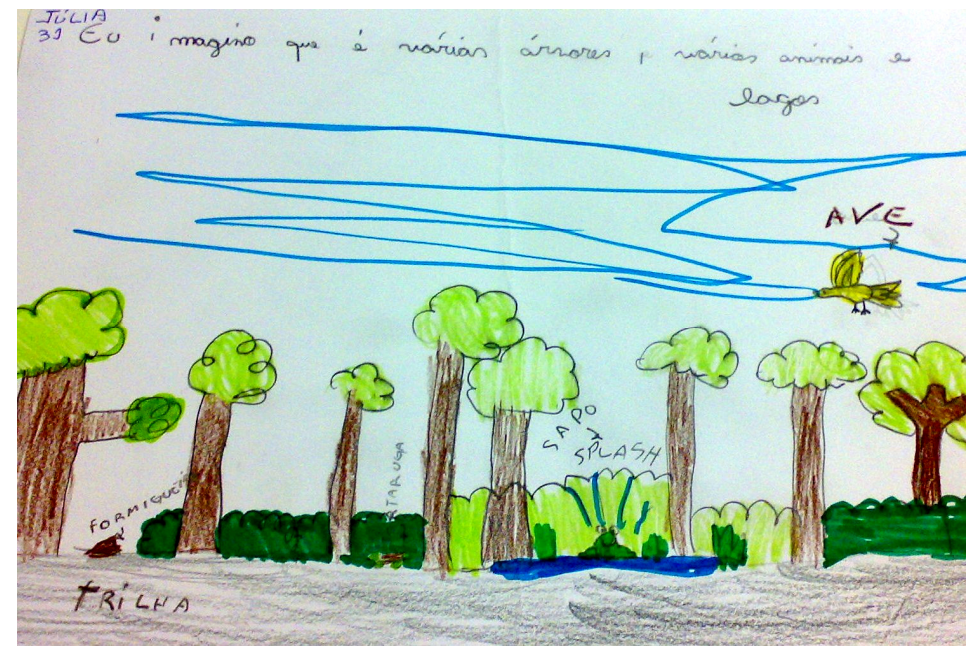

Figura 2 Desenho de pré-percepção 2

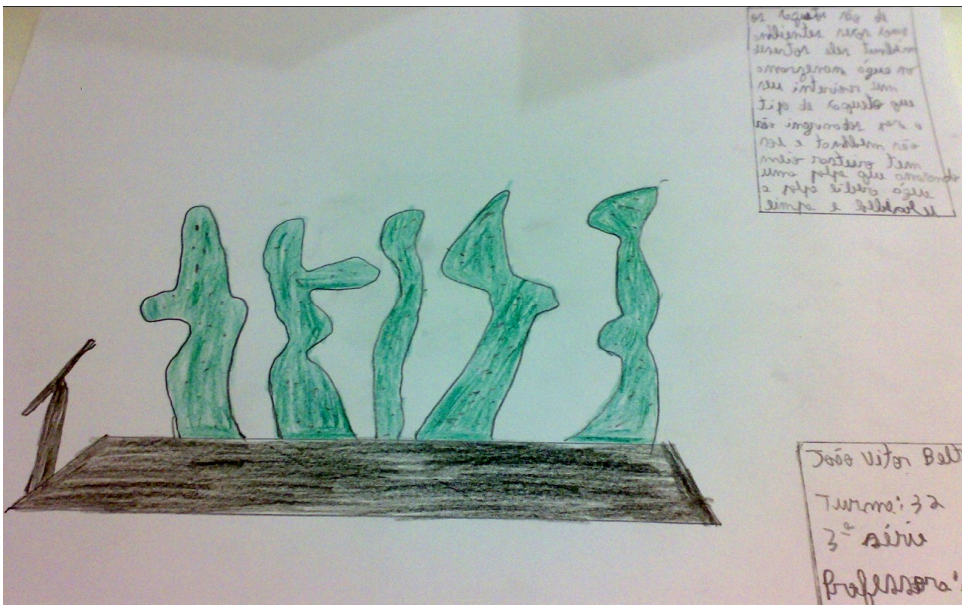

Figura 3 Desenho de pós-percepção 3

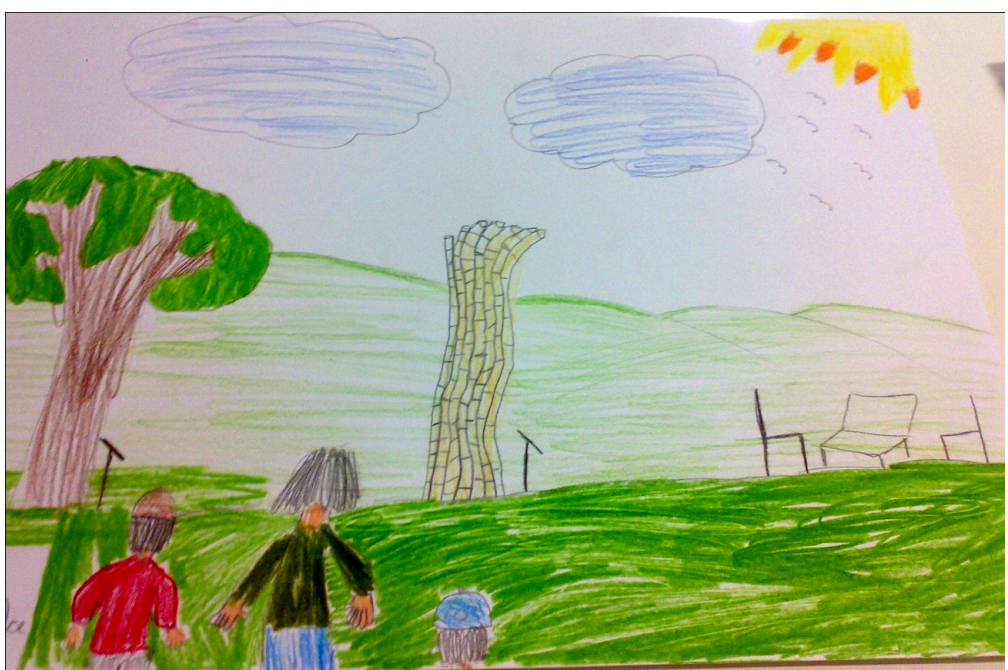

Figura 4 Desenho de pós-percepção 4 


\author{
(Revista Eletrônica do PPGEAmb-CCR/UFSM) ISSN:
}

\title{
CONCLUSÃO
}

Tendo por base a prática realizada com os alunos do Colégio Riachuello e as experiências vividas durante a monitoria de educação ambiental no Jardim Botânico da UFSM (2007-2008), é possível concluir que a prática na educação ambiental pode ser considerada efetiva por ser mais atrativa aos alunos, sendo assim, a educação ambiental realmente contribui na compreensão dos problemas socioambientais e da sua superação.

Os alunos entenderam a proposta do diálogo e participaram ativamente do processo, expondo suas concepções sobre a natureza. As discussões permitiram trocas de experiências tanto entre alunos quanto em professores que desta forma construíram conhecimentos juntos. A relevância do processo consistiu em dialogar com os alunos, analisar suas percepções, buscar novas técnicas, aprimorar práticas ambientais e valorizar o Jardim Botânico como espaço educativo.

Na prática "teia da vida", os estudantes demonstraram interesse, empenho, trabalho em equipe e satisfatório conhecimento dos assuntos abordados. Na comparação da pré e pós percepção dos desenhos das crianças, a presença humana representou uma ampliação de percepção do homem como parte do ambiente e nos poemas os alunos demonstraram consciência ecológica. Porém estes dados por si só não demonstram mudança de percepção efetiva, apenas uma pequena ampliação desta em alguns aspectos. Isto deixa claro que a mudança de percepção é um processo contínuo, que necessitará de mais vivências para se concretizar. Ainda que a mudança de percepção ocorresse nesta prática, não poderíamos afirmar que esta estabeleceria uma mudança de comportamento, uma vez que nenhuma estratégia educativa teria esse poder de garantí-la, mas sim incentivá-la. As práticas ambientais devem ser estratégias para ampliar a percepção ambiental e efetivar a ecoalfabetização.

A adaptação das práticas aos níveis de ensino segundo os PCNs permite que os monitores trabalhem com os alunos temas em que já há um conhecimento prévio, facilitando a compreensão e a revisão de conceitos, permitindo aos alunos aplicação dos conteúdos vistos em aula.

A perspectiva da ecoalfabetização utilizada nas práticas permite que os estudantes conheçam os princípios básicos que regem a vida, e passem a visualizar o ambiente como um todo, no qual o homem é apenas um fio da teia da vida. Neste sentido, a observação das relações entre os seres vivos vai se tornando gradualmente mais crítica e a visão antropocêntrica vai se transformado em uma visão sistêmica da vida. A forma de abordagem dos monitores é essencial para consolidar o ensino dos princípios ecológicos, por isso este deve possuir domínio do tema e utilizar estratégias didáticas para apresentar estes conceitos, além de incorporar estes conceitos o máximo possível em sua fala durante a visita.

As escolas através da figura da direção e dos professores podem proporcionar aos seus estudantes, saídas de estudos em ambientes não formais, como os jardins botânicos, promovendo assim a motivação na aprendizagem baseada em experiências vivenciadas. Tal estratégia sugerida aos professores é uma ótima oportunidade de desenvolver o tema transversal Meio Ambiente, assim como fazer trabalhos interdisciplinares, cumprindo com parte de seu papel institucional de responsabilidade sócio ambiental da escola.

A possibilidade verificada é que o espaço do Jardim Botânico da UFSM é rico para investigação e aprendizagem. Recomenda-se um bom trabalho de divulgação nas escolas através de carta de apresentação as escolas, folders ilustrados e participação em eventos de divulgação do 
trabalho de educação ambiental no Jardim Botânico da UFSM. A perspectiva é que o projeto continue, e que seja formada uma equipe de educação ambiental no Jardim Botânico da UFSM, com um programa permanente de educação ambiental.

Ao final deste trabalho sinto-me honrada por ter a oportunidade de contribuir para o que o Jardim Botânico da UFSM seja mais valorizado como um espaço de educação ambiental. Sou grata por todas as experiências de que vivi neste local, enquanto monitora, e é com muito carinho que este material todo foi especialmente produzido. Espero que este trabalho torne este espaço educativo mais conhecido pelas escolas de Santa Maria e região, através da divulgação do trabalho de educação ambiental via práticas ambientais e que o trabalho dos monitores seja facilitado com os roteiros à disposição, o que consolidará a educação ambiental no Jardim Botânico da UFSM.

Os roteiros de práticas ambientais apresentados nesta monografia poderão servir como estratégias educativas para os demais Jardins Botânicos Brasileiros ou até internacionais. Os professores e os estudantes começarão a perceber que um jardim botânico não é um mero jardim de plantas identificadas, nem local apenas para se fazer piquenique, mas sim reconhecendo-o como uma sala de aula sem paredes, um laboratório natural que os faz perceber-se como integrantes da teia da vida e desta forma incentivando-os a tornarem-se sujeitos ecológicos.

Finalmente, acredito que a educação ambiental não deve ser uma forma impositiva de influenciar pessoas a conservar a natureza por motivos antropocêntricos e sim uma vivência que leve a observação e compreensão dos princípios de organização da natureza, e a partir disso repensar sua ação cotidiana frente ao ambiente.

\section{REFERÊNCIAS BIBLIOGRÁFICAS}

BRASIL. Secretaria de Educação Fundamental. Parâmetros Curriculares Nacionais: meio ambiente, sáude: temas transversais. 2. ed. Rio de Janeiro: DP\&A, 2000

BRASIL, Ministério da educação e do desporto, secretaria de educação fundamental. Referencial curricular para a educação infantil- introdução. Brasília: MEC-SEF,1998.

CAPRA, F. A Teia da Vida. São Paulo, Cultrix, 2002.

F, Buckley, P., Barlow Z. Ecoalfabetização: Preparando terreno. Califórnia, Learning in the Real World, 2000.

CARVALHO, I. C.M. Educação Ambiental a formação do sujeito ecológico. São Paulo: Cortez, 2004.

DIAS, G. Ecopercepção: um resumo didático dos desafios ambientais. São Paulo: Gaia, 2004.

DUAILIBI, M. Prefácio à edição brasileira. In: Alfabetização ecológica: a educação das crianças para um mundo sustentável. São Paulo: Cutrix, 2006.

FREIRE, P. Pedagogia do oprimido. Rio de Janeiro, 17a ed:Paz e Terra,1987

HUTCHIDSON, D.Educação ecológica: idéias sobre consciência ambiental. Trad. Dayse batista. Porto alegre. Artes Médicas Sul, 2000.

INSTITUTO BRASILEIRO DO MEIO AMBIENTE E DOS RECURSOS NATURAIS. Brincando e aprendendo com a mata: manual para excursões guiadas, Projeto Doces Matas.IBAMA. Belo Horizonte,2008.

LEFF, E. Racionalidade Ambiental - a reapropriação social da natureza. Civilização Brasileira, 2006. 
(Revista Eletrônica do PPGEAmb-CCR/UFSM) ISSN:

MERCK, A. T. Metodologias interdisciplinares em Educação Ambiental: práticas ambientais. ETIC- EAD- UFSM, 2009.

MORIN, E. Cultura de massas no século XX: o espírito do tempo II: necrose. Rio de Janeiro: Forense-Universitária, 1975

E. A cabeça bem feita: repensar, reformar o pensamento. 6a ed. Rio de Janeiro: Bertrand Brasil, 2002.

Os sete saberes necessários à educação do futuro. 6ạ ed. São Paulo: Cortez, 2002.

MORIN, E.; CIURANA, E.; MOTTA, R. D. Educar na era Planetária. O pensamento complexo como método de aprendizagem pelo erro e incerteza humana. São Paulo: Cortez; Brasília, DF: UNESCO, 2007.

MINISTÉRIO DO MEIO AMBIENTE, CONAMA. Resolução no 339, de 25 de setembro de 2003. DOU 25.9.2003, seção I, pág. 60

MINISTÉRIO DA EDUCAÇÃO E CULTURA. Panorama da educação ambiental no ensino fundamental / Secretaria de Educação Fundamental $\quad$ - $\quad$ Brasil $\quad$ MEC $\quad$; SEF, http://www.crmariocovas.sp.gov.br/pdf/pol/panorama educacao.pdf acesso em 26/07/2010.

ORR, D. Ecological Literacy: education and transition to a postmodern world. Island Press, 1991.

ORR, D. In: Alfabetização ecológica: a educação das crianças para um mundo sustentável. São Paulo: Cutrix, 2006.

PEREIRA, T.S. COSTA, M. L. N. Os Jardins Botânicos brasileiros: desafios e potencialidades. Cienc. Cult. [online]. 2010,

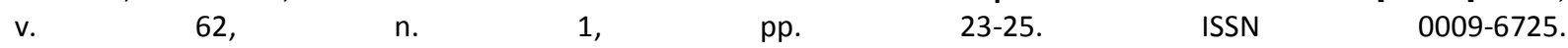
In:http://cienciaecultura.bvs.br/scielo.php?pid=S000967252010000100010\&script=sci arttext. Acesso em $26 / 07 / 2010$.

PEREIRA, T.S.; Costa, M.L.M.N. \& Wyse Jackson, P. (Org.) Plano de Ação para os Jardins Botânicos Brasileiros. Rio de Janeiro. Rede Brasileira de Jardins Botânicos. 2004.

PEREIRA, A. B. Aprendendo ecologia através da educação ambiental. Porto Alegre, Sagra Luzzatto, 1993.

SORRENTINO, M. Formação do educador ambiental: um estudo de caso FE/USP, São Paulo, SP 1995.

VALADARES, B. B. Excursão: planejando e realizando trabalho de campo em ciências. In: Revista do professor no 84, outubro-dezembro. Porto Alegre, CPEOEC,2005.

VASCONCELOS, H. R. A pesquisa-ação em projetos de Educação Ambiental in:PEDRINI, A.G. (Org.).Educação ambiental: Reflexões e práticas contemporâneas. 5ed. Petrópolis, RJ, Vozes, 2002

THAINES,E. Educação ambiental e ludicidade. In: BAGGIO, A, Barcellos, V. Educação ambiental e Complexidade: entre pensamentos e ações. Santa Cruz do Sul: EDUNISC, 2008.

WILLISON, J. Educação ambiental em Jardins Botânicos: Diretrizes para desenvolvimento de estratégias individuais. Rio de Janeiro: Rede Brasileira de Jardins Botânicos, 2003.

WILLISON, J. Educação para o desenvolvimento sustentável: diretrizes para atuação em jardins botânicos. Rio de Janeiro, Rede brasileira de jardins botânicos, Instituto de pesquisas jardim botânico do Rio de Janeiro, BCGI, 2006.

YUS, R. Educação integral.Uma educação holística para o século XXI. Artmed, Porto Alegre, 2002. 